\title{
Aplicação de teorias cognitivas ao projeto de objetos de aprendizagem
}

Liane Margarida Rockenbach Tarouco

Silvio Luiz Souza Cunha

liane@penta.ufrgs.br, silvio.cunha@ufrgs.br

Universidade Federal do Rio Grande do Sul

Porto Alegre - RS

\begin{abstract}
Resumo
Este artigo apresenta um conjunto de estratégias sendo utilizadas para otimizar o projeto e desenvolvimento de objetos de aprendizagem. Utiliza a teoria da carga cognitiva.

Palavras chaves: objetos de aprendizagem, design instrucional, teoria da carga cognitiva
\end{abstract}

\begin{abstract}
This article presents a set of strategies being used to optimize the project and development of learning objects. It uses the theory of the cognitiva load.
\end{abstract}

Keywords: learning objects, instrucional design, cognitive load theory

\section{A multimídia na educação}

A produção de material educacional digital demanda considerável esforço, especialmente quando envolve multimídia e é portanto desejável que a sua produção possa ser conseguida sem desperdício de esforço mas de forma a atender quesitos de qualidade.

Isto tem levado ao uso do conceito de objetos de aprendizagem que possam ser utilizados como peças lego, com as quais tem sido tão freqüentemente comparados.

A idéia é que objetos de aprendizagem básicos, assim como peças lego, possam ser combinados de muitas maneiras permitindo formar unidades de aprendizagem capazes de oferecer estratégias de aprendizagem

diversificadas e ajustadas às Figura 1: Metáfora lego para objetos de necessidades dos estudantes.

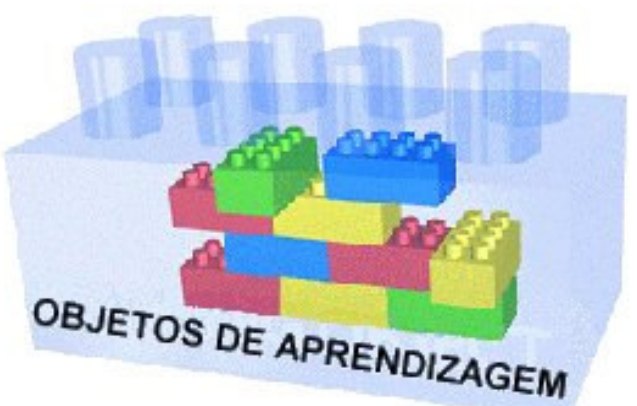
aprendizagem

Uma das formas de definir objetos de aprendizagem é: Elementos de um novo tipo de instrução baseada em computador construído sobre o paradigma da orientação a objetos da ciência da computação. Eles permitem aos projetistas instrucionais a construção de pequenos componentes instrucionais os quais podem ser reutilizados em diferentes contextos de aprendizagem (Wiley 2002). 
O desenvolvimento de material educacional digital de qualidade não prescinde o uso de multimídia, pois sua utilização tem sido amplamente reconhecido pelo potencial aprimoramento na forma como as pessoas aprendem (Mayer 2002). Todavia, conforme destacado também por Mayer em outro trabalho (2001) o uso de mais de uma mídia concorre pela atenção do estudante e seu uso indiscriminado e de forma não apropriada pode afetar negativamente o processo de reflexão, ou como ele denomina, "o fazer sentido" por inúmeras razões.

Este artigo pretende apresentar estes aspectos bem como os aportes teóricos a serem considerados no projeto e implantação de objetos de aprendizagem que serão posteriormente combinados de modo a atender a estratégia pedagógica selecionada pelo professor ou mesmo por sistemas baseados em tutores inteligentes. O projeto destes objetos educacionais deve levar em conta tanto considerações derivadas de teorias de aprendizagem como combinar o conhecimento de outras áreas como ergonomia, engenharia de sistemas e levar ainda em conta as potencialidades e limitações da tecnologia envolvida. O propósito deste trabalho é relatar também o resultado de algumas experiências realizadas envolvendo a investigação do impacto cognitivo de diferentes estratégias de projeto de objetos educacionais.

\section{Projeto de objetos de aprendizagem}

O projeto e construção de objetos de aprendizagem demandam um complexo arranjo de habilidades multidisciplinares. Conforme destacado por Polsani (2003), o processo de desenvolvimento deve ser cuidadosamente planejado e metodicamente desenvolvido, pois para produzir um objeto de aprendizagem é preciso: (a) conhecer a temática que se deseja trabalhar; (b) determinar a abordagem pedagógica que norteará sua concepção e uso; (c) saber utilizar ferramentas de autoria para sua construção e (d) trabalhar de forma coerente com os princípios de projeto educacional.

De uma maneira geral, os alunos não apresentam desenvoltura na organização de raciocínios, elaboração de estratégias de resolução de problemas, atenção, concentração, estímulo ao processo de cálculo mental. Sendo assim, as habilidades envolvidas nesse processo, tais como, tentar, observar, conjeturar, deduzir, e, que, compõem o que chamamos de raciocínio lógico, acabam exigindo uma maior atenção por parte dos professores, o que muitas vezes atrasa o conteúdo programado para ser trabalhado durante o semestre. Em contrapartida, muitos destes alunos demonstram uma desenvoltura ímpar na utilização de recursos tecnológicos. Para minimizar este contraponto novas metodologias vêm sendo estudadas, principalmente no que diz respeito ao uso de recursos de informática na educação, com a finalidade de potencializar habilidades que visam o desenvolvimento do raciocínio.

Estudos mostram que o uso integrado de ferramentas de tecnologias de informação e multimídia é apontado como capaz de proporcionar melhorias significativas no processo ensino e aprendizagem. Conforme descrito por Jonassen (1998) o uso do computador como ferramenta cognitiva implica em que seu uso pelos aprendizes sirva para elicitar o que eles sabem e engajá-los em pensamento crítico sobre o conteúdo que estão estudando. O estímulo ao pensamento crítico é essencial por inúmeras pesquisas mostram que o ensino apenas de fatos, leis e teorias não prepara os alunos para as necessidades dessa nova sociedade da informação. Ao contrário disso, sabemos que os alunos precisam adquirir capacidades de raciocínio crítico, resolução de problemas, comunicação efetiva, e ainda habilidades para acessar informação e trabalhar 
colaborativamente. A tecnologia é um fator chave nessas mudanças trazendo novas possibilidades para a educação.

Os objetos de aprendizagem devem buscar potencializar habilidades de raciocínio lógico dos alunos, levando à aprendizagem significativa. Com estas considerações como base cabe então perguntar:

a) Alunos que interagem com objetos de aprendizagem conseguem ter melhor rendimento no conteúdo das disciplinas de formação básica?

b) Será que o uso de um objeto de aprendizagem potencializa o ensino e aprendizagem dos conteúdos das disciplinas de formação básica?

\subsection{Iniciando o projeto do objeto de aprendizagem}

Segundo Singh (2000), um objeto de aprendizagem deve ser bem estruturado e dividido em três partes: objetivo, conteúdo instrucional e realimentação.

Objetivos: esta parte do objeto tem como intenção demonstrar ao aprendiz o que ele poderá aprender a partir do estudo desse objeto, também poderá conter uma lista dos conhecimentos prévios necessários para um bom aproveitamento de todo o conteúdo disponível.

Conteúdo instrucional: aqui deverá ser apresentado todo o material didático necessário para que no término o aluno possa atingir os objetivos citados no item anterior.

Prática e realimentação: uma das características importantes do paradigma objetos de aprendizagem é que a cada final de utilização julga-se necessário que o aprendiz verifique se o seu desempenho atingiu as expectativas, caso não, o aprendiz deve ter a liberdade para voltar a utilizar-se do objeto quantas vezes julgar necessário.

A organização do contexto em que o objeto de aprendizagem estará inserido passa pela busca de respostas para questões tais como:

- O que o aluno sabe?

- O que vai poder conhecer?

- O que poderia ser um ponto de entrada para uma experiência de aprendizagem?

A investigação sobre o que o estudante conhece sobre o assunto pode ser implícita ou explícita. No primeiro caso, o projetista assume que um conhecimento básico exista e possa servir de alicerce para apoiar a construção de novos esquemas mentais. A verificação pode, por outro lado, ser explícita e estar embutida na estrutura de controle de apresentação e no seqüienciamento dos objetos de aprendizagem. Alternativamente, esta verificação pode estar incluída no próprio objeto de aprendizagem que, testando o conhecimento prévio do estudante, poderia direcioná-lo para outros objetos de aprendizagem caso seja verificado que ele não detém o conhecimento embasador necessário.

O passo seguinte consiste em determinar:

- Quais são os componentes de um objeto de aprendizagem?

- O que vai em um objeto de aprendizagem?

- Como é organizado um objeto de aprendizagem? 
A seguir é preciso definir o ponto de entrada para o objeto de aprendizagem que deve atrair a atenção do estudante, conforme destacado por Gagné (2005) em sua lista de eventos de instrução (Tabela 1), dos quais o primeiro consiste em conseguir a atenção do estudante. Isto pode ser conseguido usando: uma notícia; uma situação; um caso; um filme; uma animação.

Tabela 1: Eventos de instrução de Gagné (2005)

1. Ganhar atenção do estudante visando alertá-lo para o que segue

2. Descrever o objetivo de aprendizagem para aumentar sua expectativa e levar o estudante a focalizar sua atenção

3. Estimular relembrança de conhecimento prévio trazendo-o para a memória de trabalho

4. Apresentar o material a ser aprendido

5. Prover orientação durante a aprendizagem

6. Elicitar performance (praticar)

7. Prover realimentação com vistas a reforçar a aprendizagem

8. Testar performance para ensejar verificação sobre a medida em que os objetivos de aprendizagem foram alcançados

9. Aperfeiçoar retenção e transferência das informações e conceitos ensejando sua aplicação em tarefas atuais e futuras

Um exemplo do uso desta estratégia é ilustrado na figura 2 e foi usado em um objeto de aprendizagem que visava estudar o fenômeno da difração da luz e analisar o seu efeito no processo de formação das imagens. Os objetivos do objeto de aprendizagem foram:

- Identificar e compreender alguns dos princípios básicos da óptica e da visão e os principais conceitos físicos, que permitam a ele entender o processo da formação das imagens, em especial, o efeito da difração envolvido nesse processo.

- Relacionar e aplicar estes princípios às imagens geradas nos aparelhos de televisão, monitores de computadores, telas de cristal líquido, fotografias, painéis e pinturas.

A cena inicial mostra um quadro com uma figura pontilhista, a tela de um aparelho de televisão e os dois espectadores que estabelecem um diálogo em função do que o narrador relata na televisão sobre uma exposição de pinturas que utilizam a técnica do pontilhismo. A seguir é apresentada a constituição pontilhista das imagens ao nosso redor. Isto é feito através de diálogos entre os personagens.

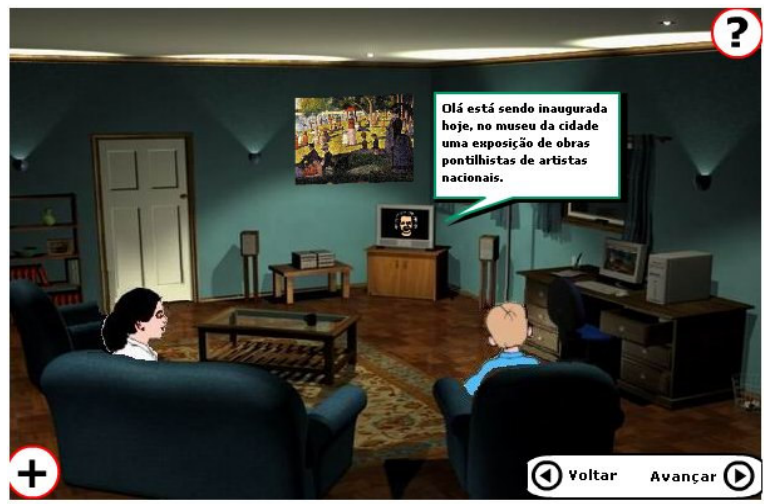

Figura 2: Evento inicial de aprendizagem, buscando atrair a atenção do aluno. 
Utilizando um "programa de televisão" o objeto de aprendizagem apresenta o conceito de difração na água através de uma simulação de um tanque de água com barreiras de tamanhos diferentes, e após o conceito de difração da luz, caracterizando o comportamento ondulatório da luz (Figura 3).

Na seqüência é apresentada uma figura do olho humano identificando as principais partes que atuam na formação da imagem, e como a imagem e formada na retina. Depois o aluno é levado a fazer algumas experiências num "laboratório virtual" onde poderá visualizar os efeitos de difração da luz (Figura 4).

Após a realização da experiência o objeto é finalizado com algumas considerações finais sobre a difração e o caráter pontilhista das imagens. Para encerrar o aluno é convidado a responder um questionário com caráter formativo, o qual possibilita ao aluno verificar seus conhecimentos sobre as idéias apresentadas no objeto. Dessa

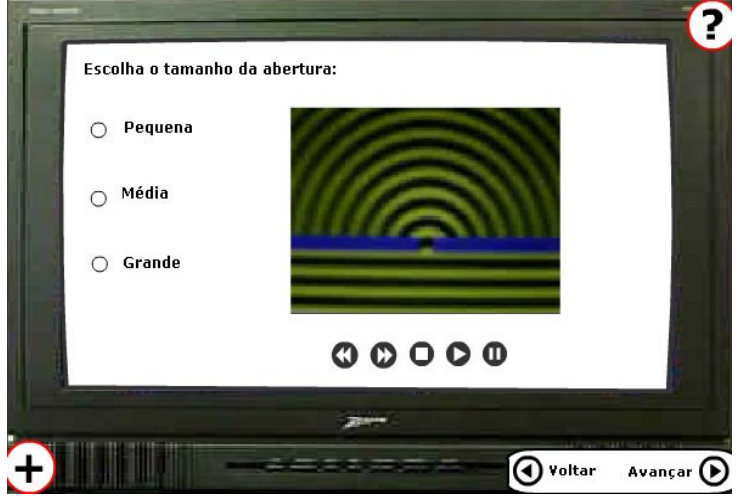

Figura 3: Cuba de ondas virtual para demonstrar o fenômeno da difração.

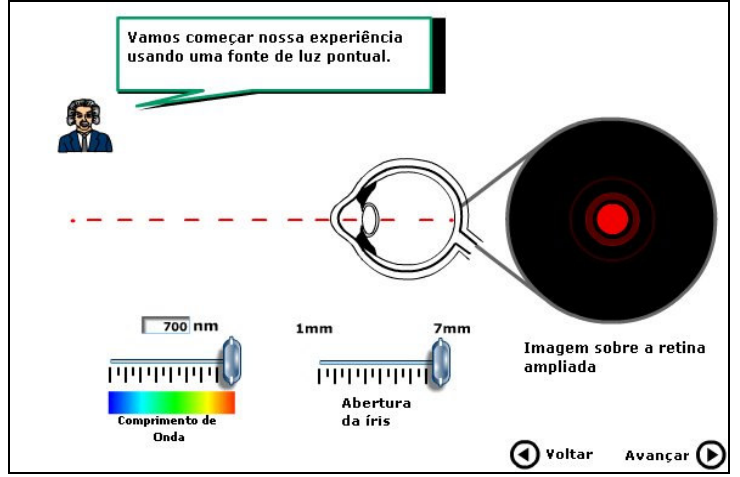

Figura 4: Formação de imagem na retina. forma o aluno tem possibilidade de voltar ao objeto e rever algum conceito que não tenha compreendido.

O projeto de objetos de aprendizagem deve buscar atender aos princípios de projeto instrucional e a relação de eventos de aprendizagem proposta por Gagné (2005) constitui elemento de orientação que facilita e norteia o trabalho do projetista.

Adicionalmente, o projetista deve dedicar atenção especial ao aspecto visual do objeto de aprendizagem, pois conforme ressaltado por Sweller (2005), a carga cognitiva precisa ser considerada sob pena de ocorrer falhas na aprendizagem.

\subsection{Conteúdo, forma e cognição}

A carga cognitiva refere-se às demandas colocadas na memória de trabalho do aprendiz durante a instrução. No caso da instrução baseada por computador ou da instrução baseada na web, o termo cobre tanto o processo mental necessário para acessar e interpretar as telas, ícones e objetos, como o processo cognitivo dedicado para processar o real conteúdo da instrução. Esta subdivisão da carga cognitiva pode ser resumida como segue:

- carga cognitiva intrínseca

- esforço que contribui para a construção dos esquemas 
- derivada da natureza do conteúdo a ser aprendido

- carga cognitiva externa ao conteúdo

- esforço requerido para processar o conteúdo em decorrência de sua estruturação e organização

- derivada do material instrucional

A primeira causa de eventual sobrecarga cognitiva (intrínseca) é derivada do conteúdo em si e não pode ser reduzida, a não ser pela segmentação do material contido em um objeto de aprendizagem. Mas o segundo tipo pode e deve ser reduzido pelo projetista. A carga cognitiva é um fator sempre presente no design de telas e interfaces de computador porque cada um dos elementos ou dos objetos da tela deve ser interpretado pelo usuário e conseqüentemente ocupa alguma energia mental do usuário. O objetivo de um bom design de página para uso educacional é, naturalmente, reduzir a quantidade de processamento direcionado à interação com o sistema e maximizando o processamento do conhecimento que está sendo ensinado.

Um design de tela complexo ou não-convencional que usa diferentes fontes, objetos, ferramentas da navegação, e padrões de layout terá geralmente uma carga cognitiva processual ou funcional elevada porque cada componente necessitará ser percebido e interpretado pelo aprendiz. Uma tela que use convenções padrão no texto, gráficos, navegação e layout será mais facilmente interpretada e conseqüentemente terá uma carga cognitiva muito mais baixa.

Adicionalmente é preciso considerar a forma apropriada de combinação dos diversos tipos de mídia que a tecnologia atualmente enseja. Mas para isto é preciso atentar para a forma como o processo de cognição ocorre. A formulação cognitivista, que tanto influenciou nossas atuais concepções educacionais, admitindo a semelhança entre o desempenho da inteligência humana e o funcionamento lógico de um computador, propõe que o pensar humano ocorre da mesma forma como um computador processa informações . O ser humano é assim considerado como um "sistema de tratamento da informação" sendo a memória constituída basicamente por uma memória de curta duração, também chamada de memória de trabalho, a memória de longa duração e um sistema de gerenciamento que determina quais as informações presentes na primeira que devem ser armazenadas na segunda. Estudos recentes mostram que este sistema de tratamento de informação dispõe de entradas independentes para a informação visual e para a verbal. Mousavi (1995) mostra que ocorre redução da carga cognitiva misturando-se apresentação visual e auditiva, pois a existência dos dois sub-sistemas separados e independentes faz com que a carga possa ser reduzida quando ambos os sub-sistemas estão ativos comparado com quando todo o processamento usa apenas um único sub-sistema.

Todavia, conforme comprovado por Mayer (2001 e 2002) a redução da carga em decorrência do modo dual de apresentação ocorre apenas quando a informação presente nas diferentes modalidades não é redundante, pois se for redundante a carga cognitiva aumenta.

Projetistas de ambientes de aprendizagem utilizam multimídia e interatividade como forma de conseguir uma aprendizagem mais eficaz. Todavia, em alguns ambientes, estes fatores podem resultar em um efeito de distração e causar um impacto negativo no processo de aprendizagem resultando num aumento da carga cognitiva, ou seja, da quantidade de recursos cognitivos alocados a uma tarefa específica, conforme destacado por Sweller (2005). 
Embora estes conceitos sejam largamente aceitos, o ensino raramente é estruturado tendo isto em mente. Os materiais educacionais digitais e naturalmente os objetos de aprendizagem freqüentemente sobrecarregam a memória de trabalho dos aprendizes e dificultam a aquisição de esquemas que requer reflexão. Aprender não é somente identificar os conceitos, mas compreender o que foi trabalhado. $\mathrm{O}$ indivíduo precisa adquirir informações gerais suficientes (aquisição de esquemas), para que possa aplicar a muitos textos diferentes.

\section{O uso de jogos educativos}

A dimensão lúdica ganha cada vez mais espaço no projeto de objetos de aprendizagem. Jogos educativos permeiam o projeto dos objetos de aprendizagem por diversas razões. A primeira e mais relevante deriva do fato de que através dos jogos educativos, o educando assume uma postura ativa. Interage com o objeto de aprendizagem e, sobretudo, vê-se diante do desafio de selecionar informações e atribuir-lhes significados. Eles começaram a ser utilizados no contexto educativo a partir do rompimento com o paradigma tradicional e surgimento do construtivismo, que enfatiza a participação e experimentação do sujeito na construção de seu próprio conhecimento, através de suas interações.

Neste sentido, os jogos educacionais podem ser um elemento catalisador, capaz de contribuir para o "processo de resgate do interesse do aprendiz, numa tentativa de melhorar sua vinculação afetiva com as situações de aprendizagem". A vinculação afetiva exerce um papel fundamental, pois, cansado de muitas vezes tentar e não alcançar resultados satisfatórios no chamado "tempo" da escola, o aluno experimenta sentimentos de insatisfação constantes os quais funcionam como bloqueadores nos avanços qualitativos de aprendizagem.

Adicionalmente, conforme destacado por Fraga (2005), a produção de jogos e o jogar possibilitam que o sujeito que aprende esteja em contato com uma forma de construção de sentido que depende dele. O jogo explora a tomada de decisão do indivíduo cognoscente possibilitando a formação de um sujeito crítico e agente do seu fazer. Conforme relatado por Fletcher (2006), o uso de jogos educativos aprimora a capacidade de resolver problemas e há relatos de casos que mostram maior ganho no processo de aquisição de conhecimento mediante jogos educativos do que se usando abordagens mais tradicionais de aprendizagem apoiada em computador. Jogos que usam simulações, tal como ilustrado na figura 5, facilitam a aquisição de conhecimento intuitivo, manifestado em respostas rápidas a questões do tipo se-então. A combinação com vídeos, tal como referido no objeto da figura 5 , agrega um elemento de motivação adicional pois o vídeo permite contextualizar melhor o conteúdo foco do processo de ensino-aprendizagem daquele material.

Estas considerações apontam para a necessidade de permear os conceitos de jogos educativos no projeto de objetos de aprendizagem. Ferramentas de autoria que facilitem a construção deste tipo de material devem ser selecionadas para promover maior produtividade da equipe responsável pela implementação dos objetos. 


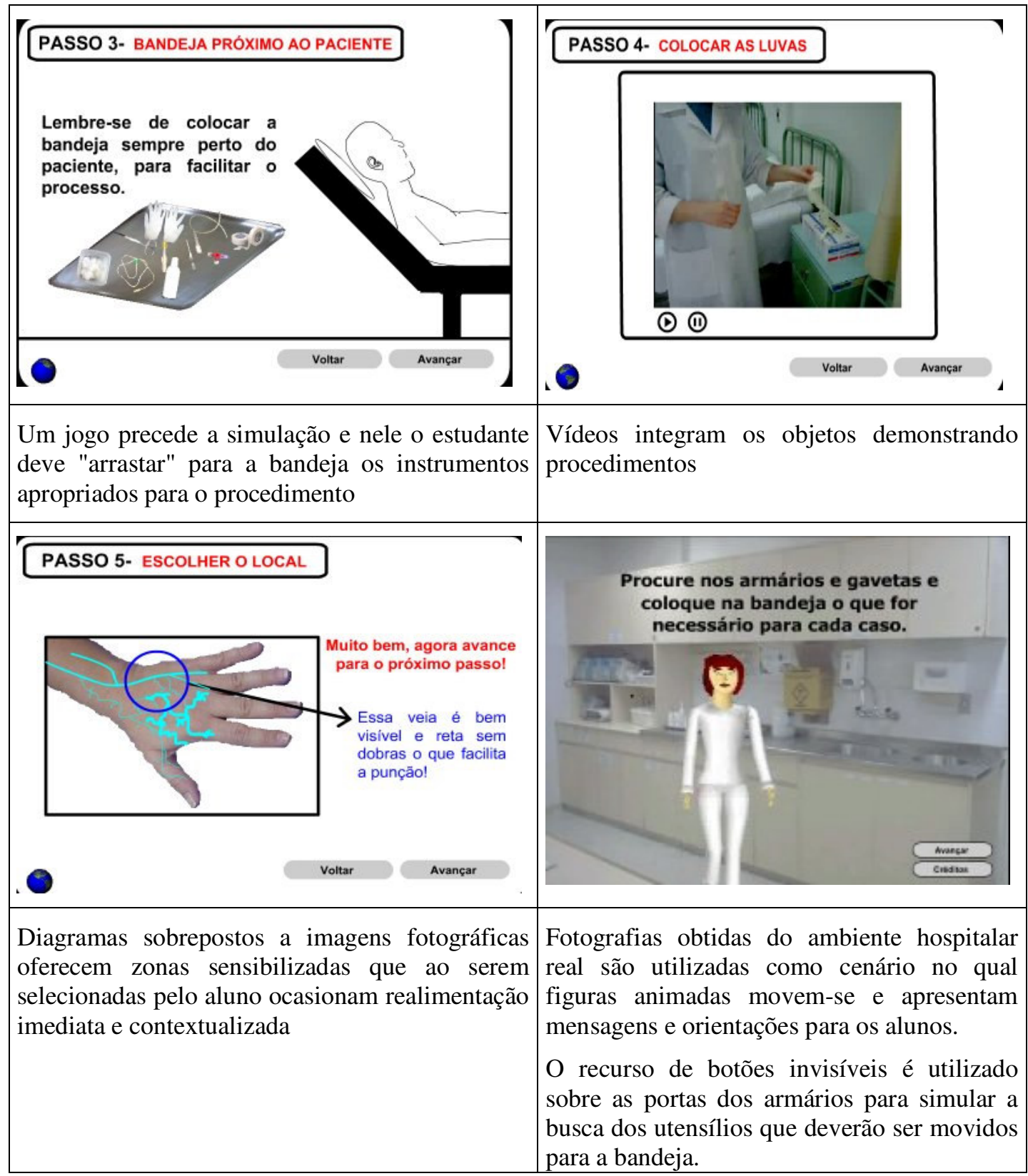

Figure 5: Jogo simulando a punção venosa

\section{Conclusões}

Com as mudanças no paradigma pedagógico e o surgimento das novas tecnologias, tais como o computador e a Internet, os professores abriram as portas ao uso de recursos que extrapolam a visão tradicional e os métodos meramente discursivos no processo de ensinoaprendizagem.

Assim, os objetos de aprendizagem se configuraram tanto como ferramenta para apoiar a educação a distância como uma ferramenta complementar na construção e fixação de conceitos desenvolvidos em sala de aula, constituindo-se em um recurso motivador tanto para o professor como para o aluno. Mas o projeto e desenvolvimento de material educacional digital pode e deve ser otimizado em tempo para projeto, especificação e implementação. Este processo passa pela análise de experiências bem sucedidas de desenvolvimento de objetos de aprendizagem com vistas a identificar as práticas que se 
mostraram mais propensas a gerar bons resultados em termos de motivação e aprendizagem. Este artigo pretendeu oferecer o compartilhamento de experiências de projeto e desenvolvimento de objetos de aprendizagem e aportar alguns subsídios teóricos que subsidiaram o projeto de objetos de aprendizagem pela equipe.

\section{Referências}

CARVALHO, A. Os Hipermédia em Contexto Educativo. CIEd - Edições: Monografias em Educação, Universidade do Minho: Aveiro-Portugal, 1999.

FLETCHER, J. D., \& TOBIAS, S. Using computer games and simulations for instruction: A research review. Proceedings of the Society for Advanced Learning Technology Meeting, Orlando, FL February 2006

FRAGA, D. Linguagem, jogo em ambiente virtual. In: Aprendizagem em ambientes virtuais. EDUCS 2005.

GRANDO, A.; KONRATH, M.; TAROUCO, L. Alfabetização visual para a produção de objetos educacionais. RENOTE-Revista Novas Tecnologias na Educação, CINTED/UFRGS, Porto Alegre - RS, V.1, N.2, Set. 2003.

GAGNÉ, R.; WAGER, W.; GOLAS, K.; KELLER, J. e al. Principles of Instructional design. Fifth Edition. Thomson. 2005.

JONASSEN, D.; CARR, C.; HUEH, H. Computers as Mindtools for Engaging Learners in Critical Thinking. TechTrends, V.43 N.2 24-32, Mar 1998

MAYER, R.; MORENO, R. Animation as an Aid to Multimedia Learning. Educational Psychology Review, V.14, N.1, March 2002

MAYER, R. E.; HEISER, J.; LONN, S. Cognitive constraints and multimedia learning: when presenting more material results in less understanding; Journal of Education Psychology, V.93, N.1, 187-198, 2001.

POLSANI, P. Use and Abuse of Reusable Learning Objects. Journal of Digital Information. S.1., V.3, N.164, Feb. 2003.

SINGH. H. Introduction to Learning Objects. Disponível em: http://www.elearningforum.com/meetings/2001/july/Singh.pdf. Acesso em 08/12/2006.

SWELLER, J.; MERRIENBOER, J. Cognitive Load Theory and Complex Learning: Recent Developments and Future Directions. Educational Psychology Review, V.17, N.2, June 2005.

MOUSAVI, S.; LOW, R., \& SWELLER, J. Reducing cognitive load by mixing auditory and visual presentation modes. Journal of Educational Psychology, 87, 319-334, 1995.

SINGH, H. Achieving Interoperability in E-Learning. Learning Circuits, March 2000.

TAROUCO, L.; COGO, A.; KONRATH, M.; GRANDO, A. Learning Through Game Authoring. Journal of Interactive Instruction Development, V.18, N.3, 28-33. Warrenton,VA - USA, 2006.

TAROUCO, L. Jogos Educacionais. Revista Novas Tecnologias na Educação. V.2 N.1, Março, 2004. CINTED/UFRGS. Porto Alegre-RS. Disponível em: $<$ http://www.cinted.ufrgs.br/renote/>. Acesso em Junho de 2006

WILEY, D. The instructional use of learning objects. 2002. Disponível em:

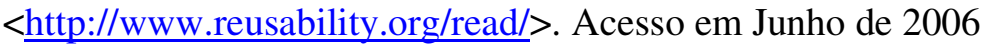

